\title{
LAS HUELLAS DE UN DIALOGO Demócratas radicales y socialistas en España y Argentina durante el período de entreguerras *
}

\author{
ALEJANDRO CATTARUZZA **
}

I.

En los últimos años, la historiografía argentina dedicada a aquello que, sin mayores precisiones, suele denominarse historia de las ideas, historia cultural e historia intelectual, ha retomado parcialmente un campo de estudios que habia quedado olvidado durante cierto tiempo: el de las relaciones entre el universo cultural español y el argentino en el siglo XX.(1) A pesar deque JoséL. Romero señalara, hace casi treinta años, tanto la importancia de la presencia española en el pensamiento argentino como algunos de los momentos cruciales de aquella relación,(2) lacuestión era desatendida o se resolvía con el argumento -cierto pero incompleto-del impacto de Ortega y de la influencia de la derecha tradicionalista y del falangismo en algunos grupos argentinos.

Dejando de lado los esfuerzos diplomáticos y del aparato del Estado, que efectivamente existieron, con diversa intensidad y múltiples sesgos ideológicos,(3) nuestra intención en este artículo es indagar las proximidades en las visiones del mundo, las relaciones, los contactos intelectuales, que tuvieron lugar en otros momentos y en otras zonas del universo político e intelectual argentino y español: las vinculadas a una tradición que llamaremos democrática radical,(4) y las de la izquierda cercana al Partido Socialista, en el período de entreguerras. Estas "definiciones" provisorias necesitan de algunas precisiones, no sólo por razones generales de método, sino porque desde su misma formulación revelan importantes

\footnotetext{
- Este artículo constituye uno de los tramos de la investigación que llevamos adelante en la Fundación Pablo Iglesias de Madrid, entre 1992 y 1993, en el marco de una beca concedida por el Ministerio de Educación y Ciencia de España.

* Universidad Nacional de Buenos Aires/ Universidad Nacional de Rosario.
} 
diferencias entre los dos ámbitos culturales a analizar. Una tradición que pudiera llamarse, como hemos hecho, democrática radical, o relacionada con el liberalismo democrático, fue notoriamente débil en la Argentina de la segunda mitad del siglo XIX e inclusive en el XX;nunca logró articularse en algún partido político estable,y cuando se expresaba lo hacia en el interior de formaciones en las que cohabitaba con otras tradiciones. Así ocurrió, entre otros, con los grupos filiables con aquella matriz ideológica que, en la segunda mitad de la década abierta en 1930, formaron parte de la Unión Cívica Radical.(5)

En España, los grupos que exhiben una estirpe ideológica similar en los años veinte y treinta -Alianza Republicana, Partido Republicano Radical Socialista, Izquierda Radical Socialista, e Izquierda Republicana, por ejemplo-pueden instalarse con cierta comodidad y precisión en el espacio de la izquierda, aun de la "burguesa".(6) En la Argentina, en cambio, ubicar a la Unión Cívica Radical oficial entre los grupos de izquierda en los treinta obligaría a realizar necesarias e innumerables aclaraciones. Demodo que, con cautela, utilizaremos la denominación "democratismo radical" para referirnos a la matriz ideológica que exhibian algunos sectores de la UCR argentina, y en España las formaciones políticas que acabamos de mencionar, y a otras cercanas a ellas.

Respecto de lo que aquí hemos llamado izquierda socialista, la cuestión parece más clara: se trata de los sectores integrantes del PSOE y del PS argentino, y de aquellos que solían deambular en sus cercanías. La determinación de dejar fuera de este análisis a los grupos del Partido Comunista obedece a que, por la época, la organicidad del funcionamiento del Comintern convierte, al menos en el caso argentino, a la sección nacional en un objeto de estudio imposible de abordar fuera del contexto de la III Internacional. Semejante objetivo excedía en mucho los límites de este trabajo. La posible incorporación al análisis de la tradición libertaria, de envergadura en ambos países, y aun del mucho más reducido mundo de los grupos trotskistas, hubiera provocado el mismo efecto.

El circunscribirnos a los grupos mencionados, a su vez, resultaba de algún interés de cara a ciertos problemas de la historia de las ideas políticas en la Argentina: tal operación permitía afrontar la cuestión de la existencia de tradiciones ideológicas de cierta perdurabilidad y solidez por debajo de los muchas veces confusos agrupamientos partidarios.

Por otra parte, debemos señalar que hemos elegido una aproximación a las fuentes seleccionadas que en muchas ocasiones se apoya en lo que Ginzburg llama indicios.(7) Esa herramienta resultaba de particular utilidad para operar sobre un horizonte documental amplio como el que nos propusimos; él está constituido por una multitud de publicaciones periódicas y libros aparecidos tanto en España como en Argentina, y en algún sentido, ha condicionado la forma que este artículo ha asumido.

Tales publicaciones, a su vez, han sido consideradas como unidades relativamente homogéneas: no se trata dehacer la historia de unas empresas culturales, sino de utilizar los datos que las revistas contienen como evidencia de la relación personal 
y politica que existía entre intelectuales españoles y argentinos. Ello no significa, desde ya, que se obviará toda referencia a la vida interna de las publicaciones o a su significación para la vida cultural de cada nación. El problema de la tirada de estas revistas, o del número de ejemplares editados o vendidos de un libro no resulta decisivo para nuestro análisis, que, insistimos, compete a un número relativamente amplio de intelectuales dedicados a la política que insinúan su modo de concebir la realidad en estos textos. Lacuestión de la apropiación que los lectores, considerados como "individuos" o como integrantes de sectores o clases sociales, y la referida a la circulación de aquellas ideas en la sociedad global, ambas de gran interés, no forman parte del problema que proponemos.

Aunque nuestra atención seha concentrado antes en los sistemas de relaciones que en las ideas, debemos señalar que el pensamiento que se expresa en este tipo de fuentes es sin duda uno mucho menos preciso y homogéneo que el de los documentos oficiales de un partido político, y también, desde ya, que el de las obras de los hombres de la "alta cultura". Las "ideas" que, en muchas ocasiones, se expresan en estos textos, son huidizas, difícilmente aprehensibles, opacas y hasta contradictorias. Con ellas, sin embargo, estos hombres procesaban su experiencia, organizaban y comunicaban su visión del mundo, e intentaban actuar sobrelas cosas y sus semejantes.(8) Es del caso señalar, alrededor de este punto, que no se trata de analizar aquí sólo, ni fundamentalmente, los diálogos que efectivamente sostuvieran, por ejemplo, dos intelectuales de prestigio como Altamira y Rodó, sino, en mucha mayor medida, los que unos casi desconocidos Barcos y Soriano entablaron. Desde ya, queda pendiente la cuestión de la "divulgación": menos crucial que en el siglo XIX, por efecto de las traducciones y en elmarco de una cultura que comenzaba, en la posguerra, a ser una "de masas", la convivencia de "grandes pensadores" con sus "divulgadores" continúa siendo problemática.

Naturalmente, hemos evitado la suposición de que la existencia de aquellos contactos implicara obligatoriamente identidad ideológica;(9) sí presumimos, en cambio, que ella posee alguna significación en el plano de las ideas, que es la que aquí se pretende recuperar.

En cuanto al período propuesto, que es el de entreguerras, debe recordarse que él no suele figurar en las periodizaciones globales de la historia argentina. Tanto en las versiones revisionistas como en aquellas que la historiografía universitaria comenzó a proponer luego de 1955 -con algunas excepciones-, la década que se iniciaba en 1930 no sólo era considerada muchas veces susceptible de estudiarse como una etapa casi autoexplicable, sino que además se la suponía homogénea.(10) El examen de los años veinte y treinta en conjunto que aqui proponemos permitirá la reconsideración de algunas circunstancias especificas de la historia cultural argentina, y simultáneamente, atendiendo a nuestro objeto de estudio, hallar posibilidades de indagar las relaciones con el mundo europeo. En este mismo sentido, sehace necesario anticipar que la Guerra de España constituye un momento con peculiaridades muy marcadas, que sólo analizamos tangencialmente. Si por una 
parte la presencia de una colonia española muy amplia convertía a la presencia republicana en la Argentina en una cuestión de estado, por otra la polarización de las posiciones ideológicas durante la lucha obligó a definiciones tajantes y precisas, que borraron matices de importancia presentes en la etapa previa. Así, hemos entendido a la Guerra Civil como el periodo en que se intensifican unos vínculos que eran previos, y aquel en el que se definen algunos de los senderos de incorporación que recorrerán quienes lleguen luego de 1939.

Si bien el problema que planteamos se halla en el cruce de dos realidades e intenta la aprehensión de relaciones bilaterales, las conclusiones que propondremos en este trabajo, tal como hemos venido sugiriendo, competen mucho más a la historia de las ideas politicas en la Argentina que en España. Hemos preferido, en esta oportunidad, concentrarnos en tal dirección dada la persistencia que algunas imágenes del pasado muestran en la historiografía argentina: todavía en los ochenta, se sostenía que la izquierda habia sido reformista y parlamentarista desde siempre, - que no había percibido ni el problema del imperialismo ni la llamada cuestión nacional. A su vez, la UCR oficial de los años treinta era inapelablemente calificada de conservadora progresista o liberal, y como señalamos, la presencia española era reducida a grupos de la derecha o arrinconada a la etapa posterior a la Guerra Civil. Entendimos entonces que los resultados alcanzados en este tramo de la investigación resultaban más significativos si se los confrontabacon un contexto historiográfico como este.(11)

II.

La preocupación por la situación política de la que fuera la América española, el intento de diálogo con intelectuales de aquella región, la idea -muchas veces expresada con vaguedad- de que España y sus antiguas posesiones conformaban un espacio unitario, al menos desde el punto de vista cultural, e inclusive cierta vocación "panhispanista", no constituyen actitudes que carecieran de antecedentes en la España que presenciaba el desarrollo de la Gran Guerra.

Así, por ejemplo, en la segunda miiad del siglo XIX, grupos del liberalismo democrático español(12) habian impulsado una "ofensiva cultural" en torno a algunas de aquellas cuestiones. Una de las empresas más significativas en ese esfuerzo, la revista La América. Crónica hispano-americana, hablano sólo registrado entre 1857 y 1886 los avatares de las inestables repúblicas americanas, sino que en muchas ocasiones el análisis detales procesos quedaba a cargo de intelectuales americanos, como Juan Bautista Alberdi.(13)

A fines de siglo, en particular luego de 1898 , el interés español parece reavivarse;(14) la prensa periódica porteña, a su vez, constituye un espacio donde hombres como Unamuno se expresan con frecuencia en la primera década del siglo. Mientras tanto, algunos intelectuales latinoamericanos(15) como Rodó y el socialista argentino Manuel Ugarte comienzan ya hacia 1900 una reflexión que terminará 
enlazando -en ocasiones, más en la versión que surgirá de la lectura que grupos políticos realizarán luego que en los textos originales- los temas del antimperialismo ético frente a los Estados Unidos, de la necesidad de la unidad continental defensiva y de las posibilidades de existencia o construcción de una identidad cultural hispanoamericana.

Estos grupos, naturalmente, realizaban un recorte sobre el conjunto de la herencia política y cultural española: la de la "España negra" era habitualmente excluida del rescate a comienzos de siglo. Los españoles, por su parte, parecieron atar su éxito en la empresa hispanoamericana a la propia modernización y "regeneración" nacional.(17) El éxito del Arielde Rodó -prologado por Altamira-en España, y la calurosa bienvenida que brindó al texto Clarín en 1900, asi como las relaciones personales e intelectuales entre el propio Rodó y Altamira y la atención que merecia Ugarte (que se prolongaria muchos años) parecen pruebas reveladoras de la existencia de aquel nuevo diálogo.(18) Hacia el Centenario, por otra parte, varios intelectuales argentinos se dedicaron a la reconsideración de la cuestión españolae hispanoamericana: Rojas, Gálvez y Larreta.(19)

Formando parte de esta constelación de relaciones intelectuales -que incluian algunos esfuerzos estatales-, (20) se ubican aquellas que afectan más directamente a las ideas que sostienen los grupos politicos. Tanto en el contexto argentino como en el español, porla época, las funciones y roles del político y del intelectual aparecen sumamente entrecruzadas, pero aun as i pueden señalarse algunas vias de reiación especffica. Por una parte, la difusión del krausismo en la Argentina,(21) que contribuyó a conformar el todavia impreciso y vago pensamiento de la Unión Cívica Radical; ese legado, junto al reconocimiento de los divulgadores españoles, recorre el ideario radical hasta al menos mediados de la década de 1940, cuando el mundo de referencias explicitas de los intelectuales radicales solia incluir sistemáticamente a Krause, Salmerón y Giner de los Ríos. En este punto puede suponerse también, aunque no se cuenta con estudios específicos sobre el tema, que la herencia del pensamiento de Joaquín Costa en Leandro Alem, uno de los fundadores de la Unión Cívica Radical era importante.

En segundo lugar, el posible vínculo entre los sectores conservadores reformistas que, en la Argentina, propondrán la modificación de la ley electoral que, entre 1912 y 1916, permitió la llegada al poder de la UCR en los primeros comicios limpios, y grupos españoles del conservadorismo regeneracionista.(22) $Y$, finalmente, invirtiendo el sentido de la relación, puede contarse la presencia de información latinoamericana, y en particular argentina y mexicana en las páginas de El Socialista de Madrid. Este último caso merece sin embargo algunas aclaraciones: El Socialista era un diario destinado a la información general, y no una herramienta de discusión teórica. Así, las noticias de México son las referidas a la evolución de la guerra; en el caso de las noticias argentinas, ellas suelen referirse a la situación del Partido Socialista, y a algunos de sus dirigentes, en particular Juan B.Justo. Ello puede atribuirse, más que a una inquietud latinoamericanista, a la circunstancia de que el PS argentino era 
de hecho el más potente de Hispanoamérica, y había constituido el modelo organizativo de algunos de sus vecinos: más que "noticias latinoamericanas", se trata de "noticias socialistas".(23)

Parece evidente, entonces, que estos contactos y preocupaciones comunes no fueron producto del clima de ideas imperante en el período 1914-1918, sino que poseian su propia historia. Sin embargo, los procesos politicos y sociales que tuvieron lugar a partir de aquellos años y su impacto en el plano de las ideas (la Gran Guerra, el desengaño de la izquierda belicista y el resurgimiento del pacifismo revolucionario; la Revolución de Octubre que, en torno al punto que nos ocupa, dotará de nuevo interés y permitirá la reinterpretación de la Revolución Mexicana; ya entrados los veinte, la aparición del fascismo como fenómeno todavía especificamente italiano; la difusión en la izquierda de los temas del imperialismo) permitirán que ellos comiencen a recorrer nuevos caminos.

Contribuyeron también a producir tales modificaciones algunos fenómenos que se verificaban tanto en la sociedad globalcomo en el campo cultural argentino, desde aproximadamente 1910: la aparición de un nuevo público lector en las ciudades, vinculado tanto al crecimiento urbano como a la alfabetización; el comienzo de la creación demúltiples empresas culturales, cuyo auge se produce entre 1920 y 1940 , que asumian la forma de revistas literarias, políticas o de información general, y de editoriales que apuntaban a llegar a los sectores populares y, en algunos casos, específicamente a los grupos obreros, esforzándose por "crearlos" como público lector.(24)

En un nivel diferente, el asentamiento de los inmigrantes españoles que habían llegado desde fines de siglo, y la continuidad de la corriente, a pesar del porcentaje relativamente alto de analfabetismo, creaban un sector de lectores específico al que se le ofrecian publicaciones gestadas por las entidades de la propia colectividad. En ocasiones, esos intentos ostentaban un claro sesgo político, y participaban en ellos intelectuales argentinos ligados a los partidos, como el todavía socialista Benito Marianetti o el anarquista -y ocasionalmente trotsquista- José Gabriel.

Así parece comenzar un proceso de aproximación que, atravesando los años veinte y los treinta, alcanzará su momento de mayor intensidad durante la Guerra Civil, y que, como anticipamos, permitirá en muchos casos la organización de las redes, los circuitos y las vías de inserción en el momento del exilio.

En el horizonte que acabamos de diseñar, una revista como España puede brindar ejemplos del tipo de relaciones que, sostenemos, se establecía. La revista, que aparece en Madrid entre 1915 y 1924, tuvo como directores sucesivos a Ortega y Gasset (1915-1916), a Luis Araquistain (1916-1923), y a M. Azaña en sus últimos números, y ha sido atinadamente definida como "una revista de 'izquierda' en el sentido moderno del término".(25) España recibía y comentaba muchas publicaciones aparecidas en las capitales hispanoamericanas, y en Buenos Aires en particular; incluso llega a reproducir articulos tomados de ellas. Una lista incompleta incluye, por ejemplo, a Repertorio Americano (San José de Costa Rica), Pegaso (Montevideo), 
Cronos(Bogotá), Cuba Contemporánea(LaHabana), Cultura Venezolana(Caracas); entre las publicadas en Buenos Aires se cuentan Hebe, Inicial, Ideas, Vida Nuestra y Nosotros, que a su vez tomaba articulos de la revista española. El sistema de distribución de Españallegaba a muchas de estas ciudades, y la revista cuenta con una "sucursal" en Buenos Aires.

Estos vínculos también manifestaban su existencia en la fuerte atención dispensada a autores hispanoamericanos: desde ya Rubén Darío y Lugones, pero también Rodó, Ugarte, Gabriela Mistral, Alberto Ghiraldo, Carlos Pereyra, Alfonso Reyes y hasta unos todavía muy jóvenes Martínez Estrada y Borges. Ella puede intentar explicarse por el prestigio literario internacional de algunas de estas figuras; tal hipótesis debe descartarse si se atiende a la presencia de secciones, aún discontinuas, que se dedican aproblemas tan especificos como los del "espartaquismo en la Argentina", y se titulan "Crónica Americana", "Problemas Hispanoamericanos", "Aspectos Prácticos del Hispanoamericanismo", "Letras de América" y "Notas Mexicanas"; o a la realización de una encuesta impulsada por Araquistain -cuyos resultados se publican durante varios números- sobre "El Nuevo Hispanoamericanismo".(26)

Precisamente la cuestión de la Revolución Mexicana es seguida con particular atención, fundamentalmente desde 1920; es probable que el fin de la Gran Guerra -que había sido uno de los temas centrales en la revista- $y$ la firma de los acuerdos de paz abrieran la posibilidad de que la mirada de España se detuviera en aquel proceso. A su vez, como señalamos, los sucesos de 1917 en Rusia dotaban de nuevo interés a un proceso que, más allá de contenidos ideológicos diversos, también era entendido como revolucionario. Los artículos especificos sobre la situación mexicanamenudean, y en muchas ocasiones llevan la firma de Carlos Pereyra, que todavía, por aquellos años, exhibia un pensamiento fuertemente radicalizado.

Laselección que la revista española efectúa sobre elmaterial hispanoamericano al que tenía acceso resulta significativa respecto de algunas de sus actitudes ideológicas. Así, aunque en 1918 los inicios de la Reforma Universitaria de Córdoba habían sido ignorados -quizás curiosamente-, en 1920, cuando el movimiento alcanza dimensión continental, España recupera elogiosamente un manifiesto de la Federación Universitaria Argentina, al que adhieren los estudiantes catalanes, en el que se proclama antimperialista, latinoamericanista y pacifista.(27) En este último punto debe recordarse que España, como casi toda laizquierda española, había sido aliadófila durante el conflicto, al que solia leer como el enfrentamiento entre la civilización y el militarismo; en 1920, sin embargo, ya comienzan a hacerse frecuentes en sus páginas las manifestaciones de oposición "a toda guerra".(28)

En aquella misma línea se sitúan las menciones al artículo de José Ingenieros, titulado "Por la Unión Latinoamericana", aparecido en la revista Nosotros de Buenos Aires, y el apoyo que C. Rivas Cherif brindará a las propuestas, también latinoamericanistas, que Manuel Ugarte planteaba en Eldestino de un continente, de 1924.(29) 
Desde ya, puede argüirse que tanto la preocupación por la situación americana como la actitud que se asume ante ella -y también ante cualquier otro tema- es producto de las inclinaciones de los individuos más destacados en la concepción y ejecución del emprendimiento. En este caso particular, Luis Araquistain, uno de los directores de España como hemos señalado, parecía especialmente interesado en el análisis de las cuestiones hispanoamericanas; entre 1917 y 1930 aludirá recurrentemente a la posible vigencia de este espacio como una comunidad cultural. Una década después de la desaparición de España, parte de estos aireshispanoamericanistas reaparecerán en Leviatán, también dirigidapor Araquistain.(30) Sin embargo, si se atienden a otros datos, la atribución de ese interés a un individuo se torna difícil, y se fortalece la imagen de la existencia de sectores del mundo politico y cultural español que pensaban, de modos diversos, en aquella comunidad.

Así, por ejemplo, el luego radical socialista Marcelino Domingo, también colaborador de España, publicaba en 1923 su libro La isla encadenada, luego de un viaje al Caribe. Manuel Azaña firmaba en La Pluma muchos de los comentarios de libros dedicados a Latinoamérica, entre 1920 y 1923, mientras que Rivas Cheriff había anticipado en 1922, desde el mismo medio, su apoyo a las tesis de unidad hispanoamericana de Manuel Ugarte, que desplegará luego desde España.(31) Inclusive La Gaceta Literaria, más preocupada por la divulgación de las obras de vanguardia, se proponia "conseguir una dimensión americana que, si bien logró en el plano de las colaboraciones y hasta en el dominio editorial, fracasó rotundamente como proyecto político a raíz de la destemplada polémica que sucedió a un editorial.... ('Madrid, meridiano intelectual de Hispanoamérica'), violentamente replicado desde La Habana a Buenos Aires".(32)

Por estos mismos años aparecerá en Madrid Post-Guerra, una revista de menor duración que las menciondas, dirigida por Balbontín y Giménez Siles,(33) en torno a la cual se organizará, un año más tarde, en 1928, Ediciones Oriente, una de las más importantes entre las editoriales "de avanzada".(34) En prácticamente todos sus números aparecerá también la cuestión hispanoamericana, esta vez analizada en clave abiertamente antimperialista. Si bien las lecturas previas denunciaban la expansión norteamericana, los ecos de la condena moral de principio de siglo eran en ellas muy fuertes; en Post-Guerra, en cambio, el discurso recoge tanto las discusiones internacionales sobre la cuestión, que ya habian sufrido el impacto de la difusión de las opiniones de Lenin, a través de El imperialismo, etapa superior del capitalismo (1917), y también el de las polémicas en la III Internacional, todavía en desarrollo.

La revista denuncia la acción norteamericana en Nicaragua y critica a los representantes de las demás naciones en la Iv Conferencia Panamericana de La Habana, por haber "sacrificado la independencia de sus respectivos países a la dominación yanqui". También adhierea la Liga Intemacional Antimperialista, designa a Sotomayor corresponsal en París, encargado de "informar sobre el movimiento avanzado hispanoamericano", publica el libro de Juan Andrade China contra el 
imperialismo, que luego, en versión de la editorial Claridad, circulará por América Latina. Haya dela Torre, el dingenteperuano fundadordel APRA, quepor ese entonces sostenía todavía amigables discusiones con la III Internacional, también verá publicado un articulo con su firma en Post-Guerra, en el cual se halla presente buena parte de sus planteos centrales: unidad latinoamericana, antimperialismo, exaltación del movimiento de la reforma universitaria, elogio de los intelectuales europeos del compromiso, como Romain Rolland o Barbusse.(35)

Quizás este patrimonio ideológico parcialmentecomún, y aun los referentes más inmediatos que estos grupos ostentaban, se revele con particular claridad cuando Post-Guerra salude la aparición de la revista América Libre, de La Habana, apoyando sin dudar su lema: "Por la unidad interpopular americana, contra el imperialismo capitalista, en favor de los pueblos oprimidos, por la revolución en los espiritus".(36) Desde el antimperialismo, aprista o cominteriano, hasta Barbusse y la prédica de los grupos Clarté, prácticamente todo el mundo mental de la izquierda americana -y de parte de la española-se hacen presentes en estas propuestas. Cabe aqui agregarque el lema de la revista cubana, apoyado por la española, contenía a su vez al de Claridad, que aparecía en Buenos Aires. Si atendemos aun brevemente a las características de este último intento, nuevas coincidencias parecen dibujarse: Claridad era la publicación periódica de un grupo que había organizado un Ateneo y una editorial del mismo nombre, que desde los tempranos años veinte publicaba trabajos de prácticamente toda la izquierda argentina y aun latinoamericana, y que se esforzaba por difundir la literatura "social" y pedagógica entre los sectores populares. Empeñada en esa tentativa, la editorial homónima y organizada alrededor de la revista apelaba a los mismos autores y textos que las editoriales de izquierda españolas (la ya citada Oriente, Cenit, Zeus, España, La Historia Nueva, Ulises): Remarque, Frank, Anatole France, Upton Sinclair, Gorki, Ehrenburg, desde ya Barbusse y Rolland, y también Silone, Zweig y Ludwig, entre muchos otros. Las atenciones que dispensaba a las figuras políticas o literarias de la izquierda española eran también muy evidentes.(37)

Debemos señalar sin embargo, para precavemos de ofrecer la imagen de una identidad absoluta, que en el caso de la izquierda latinoamericana que se expresaba en Claridad el elemento común más visible, y el eje de los debates, hasta aproximadamente 1935-1936, era la cuestión del imperialismo. A ella venian atadas las de la caracterización de la etapa de la revolución que habría de cubrirse; la de los actores sociales que debían convocarse al frente antimperialista, asociada a la de la constitución de sujetos sociales revolucionarios alli donde el proletariado no era la fuerza más abundante entre los sectores populares; la de las llamadas burguesías nacionales y su papel en el proceso de transformación. Si bien algunos de estos asuntos están presentes en las discusiones españolas, nunca parecen alcanzar el rango de problemas centrales que tenlan para la izquierda de América Latina que hablabadesde Claridad.

Post-Guerra, entonces, no sólo asume la cuestión latinoamericana sino que se 
ubica concerteza frente a ella. Pero, además, la revista se hace eco de una discusión ya mencionada, que será evocada una y otra vez en los quince años siguientes,(38) ubicada en la zona de cruce -muy amplia en la época-entre la política y las letras. Tal debate se produjo, inicialmente, entre La Gaceta Literaria de Madrid, y Martín Fierro de Buenos Aires, en torno a la afirmación que efectuara la primera de ellas, acerca de que el "meridiano cultural" de Hispanoamérica pasaba por Madrid.(39) Más allá de que los términos de aquel debate suenen hoy cuando menos curiosos, su existencia, su amplitud y su permanencia en el imaginario de los intelectuales, que lo evocaban incluso en el exilio posterior a 1939, sugiere con claridad que el mundo latinoamericano formaba parte importante del horizonte mental de los intelectuales españoles.

Las relaciones que venimos indagando se revelaban también de otros modos. Por ejemplo, y como señalamos, alrededor de la tarea editorial: una aproximación breve a los catálogos -hasta ahora, reconstruidos sóloparcialmente- de las editoriales de izquierda argentinas y españolas evidencian tal como planteamos la existencia de una biblioteca común, conformada por los grandes referentes de la literatura "social" de la época, y por los autores que garantizaran un cierto éxito en las ventas, mientras no se alinearan con "la reacción". Esta coincidencia no resulta demasiado sorprendente; se trata en general de intelectuales de prestigio reconocido por las diversas jerarquías y secciones nacionales de la "república de las letras".

En este sentido, no debe olvidarse que cuestiones estrictamente comerciales aparecen involucradas en el negocio editorial: hacia el fin de la Gran Guerra, Hispanoamérica se ha constituido en mercado potencial para alrededor del $50 \%$ de los libros editados en España.(40) Ello, por un lado, condiciona la elección de títulos; por otro, dota de una dimensión menos precisa desde el punto de vista de las ideas políticas y estéticas a la citada polémica sobre el "meridiano cultural". Esta circunstancia no dejó de ser advertida por los propios polemistas.(41)

Es teniendo en cuenta estos elementos -que en absoluto anulan la significación ideológica del propósito- que debeleerse la declaración de la editorial Historia Nueva, cercana a Oriente, en 1929: "Queremos hacer de Historia Nuevael vehículo, el medio de unión y organización de todos los hombres comprometidos en el esfuerzo de reconstruir la unidad espiritual de los pueblos de lengua hispánica".(42)

De todos modos, una de las herramientas más utilizada por los intelectuales dedicados a la política era naturalmente el libro, y en esos objetos también hallamos huellas de contactos y cercanias. Un texto del republicano español Rodrigo Soriano, queconoció varias ediciones y diversos títulos, apareció en Buenos Aires hacia 1930. con el sello de la editorial Claridad. En esa oportunidad, el libro se tituló España bajo el sable. La dictadura; treinta años de combate; en junio de 1931, ya instaurada la República, ediciones Claridadde Madrid publicaba elmismo texto al que se agregaba un epílogo referido al período abierto el 14 de abril, bajo el título La revolución española: 1931. Ayer y hoy. En 1936, luego delcomienzo de la Guerra Civil, laeditorial Pax, con sede en Santiago de Chile y en México, volvió a editar el libro con el título 
original. En las ediciones argentina y chilena, se incluye un elogioso prólogo de Julio R. Barcos.

$\mathrm{El}$ "caso" puede ejemplificar varios de los procesos que hemos mencionado, y las mutuas atenciones que los intelectuales dedicados a la política, tanto los argentinos como los españoles, se dedicaban. Soriano tenia una larga trayectoria como diputado republicano, quedando a su cargo la petición de revisión del proceso a Ferrer. A comienzos de siglo, junto a Blasco Ibáñez, realizó actos contra la monarquía en algunas capitales europeas, y había sufrido destierro y exilio junto a Unamuno durante la dictadura de Primo de Rivera. En 1906, por otra parte, fundó el diario España Nueva, del que sería director gerente. En los años veinte, había desarrollado tareas de propaganda en Hispanoamérica, a través de conferencias y publicaciones.

Julio Barcos asume las mismas posiciones que Soriano, y no sólo ante la situación española: prácticamente es la voz de Soriano la que habla en el prólogo. Así, Barcos señala que el "drama político español" constituye "el conflicto histórico de dos civilizaciones: la feudal del siglo XIII y la democrático-revolucionaria del siglo $\mathrm{XX}^{\prime} ; \mathrm{y}$ que las "tres castas voraces y predatorias....: terratenientes, clérigos y militares" no sólo expolian a la Nación, sino que la sumen en la ignorancia.(43) EI diagnóstico -y también las soluciones, que Barcos, con algún matiz, propondrá para la Argentina pocos años después- es idéntico al que el propio Soriano ensaya en su obra:

-Para que se regenere España preciso es sacudirla de arriba abajo.... Mientras la casta militar no desaparezca y con ella la casta clerical, la casta plutócrata, la casta caciquil, las privilegiadas castas, y sea España el pueblo respetuoso de sus derechos, de la igualdad social, de la milicia ciudadana, como son ya hoy los modernos paises, será inútil todo intento de civilizada vida".(44)

La biografia intelectual y política de Julio Barcos, a su vez, es curiosa, aunque no excepcional entre los militantes argentinos. Vinculado inicialmenteal anarquismo, solia dedicarse a temas educativos, habiendo sido publicados algunos de sus libros en España y otros países europeos. En los tempranos años veinte participó de la experiencia que llevaría a la fundación de Claridad, ya mencionada; la revista lo contó durante mucho tiempo entre sus firmas habituales. Esa circunstancia junto a la publicación de sus trabajos en la misma editorial, y a su participación en otros emprendimientos de este tipo, lo ubican en el núcleo de la joven intelectualidad de izquierda de la Argentina de entreguerras, junto a César Tiempo, Leónidas Barletta, Elías Castelnuovo, Antonio Zamora y, en general, el grupo de Boedo.

Hacia la época en que escribió el prólogo al libro de Soriano, Barcos se hallaba en tránsito hacia la Unión Clivica Radical, a la que ingresaría por la llamada izquierda del partido, para luego, sin abjurar de tal identificación, apoyar a la dirección de la organización, en manos de Alvear. Durante los años treintay los tempranos cuarenta 
continuará participando en múltiples intentos vinculados al campo cultural; en el momento del triunfo del Frente Popular en España, desde el radicalismo, Barcos exaltará una y otra vez el modelo de la "Revolución Española".

Comienza de esta manera a dibujarse una relación ciertamente estrecha entre miembros de la Unión Cívica Radical argentina y españoles vinculados a la izquierda republicana, que llegaba a incluir en el manifiesto fundacional del Partido Radical Socialista, de 1929, el anhelo de construir "una gran federación de toda la comunidad iberoamericana".(45)

A los casos mencionados puede sumarse el de Luis Boffi, también prologuista y declarado admirador de la obra intelectualy politica de Alicio Garcitoral, funcionario republicano y dirigente del Partido Radical Socialista español hasta 1935.(46) Boffi señala, además, que los Cuadernos de Cultura de Valencia, en los que Garcitoral habia publicado algún trabajo, formaron parte del material que se recibía y discutía entre los estudiantes universitarios radicales.(47) Ya iniciado el exilio, G.Storni, otro dirigente de segunda línea del radicalismo argentino, será colaborador habitual de Pensamiento Español, la revista que en 1941 fundaron y dirigieron, en Buenos Aires, el Gral. V.Rojo y A.Castelao, entre otros.(48)

Uno de los varios proyectos editoriales de los que participaron tanto Barcos como Boffi y Storni fue el de la revista Hechos e ldeas,(49) que merece un análisis detenido. Nacida en el seno de la UCR en 1935, con la intención explícita de discutir y delinear con precisión la "doctrina" del partido -que los propios miembros de la redacción entendian todavia difusa-, formó parte de un esfuerzo que algunos intelectuales radicales realizaron por modemizar la organización. Hechos e ldeas se dirigla a los cuadros medios, a los militantes de base con un nivel de instrucción elevado, y a los intelectuales que formaban en las filas de la UCR. Las operaciones culturales que realizaba ratifican esta idea: traducciones sistemáticas y veloces de artículos referidos a temas económicos o jurídicos que exhiben un perfiltécnico muy marcado; crítica de unagran cantidadde libros editados en la Argentinao Latinoamérica; números monográficos dedicados a los planes económicos o a los diversos aspectos del fenómeno totalitario.

Desde una perspectiva vinculada a la historia de las ideas, el análisis de esta publicación permite el cuestionamiento de algunas opiniones admitidas respecto a las tradiciones ideológicas presentes en la UCR oficial en los años treinta: antes que el liberalismo conservador que suele atribuirse a esta formación, en Hechos e Ideas se revela una tradición democrático-radical, en ocasiones jacobina. Sin duda, una definición de este tipo obvia los matices y diferencias que efectivamente existían entre los distintos autores; a pesar de ello, el complejo de ideas que se muestra más fuerte y extendido es el que acabamos de mencionar.

En la publicación abundan los datos que denotan con claridad la presencia de referentes españoles, que se recogen de un arco relativamente amplio de la izquierda -quizás las únicas excepciones la constituyan por una parte el PC, y por otra el POUM, aunque notas de intelectuales trotskistas europeos como Souvarine o Serge eran 
publicados-, aun cuando durante la Guerra Civilse incorporen a ellos republicanos de otras procedencias, como A. Ossorio y Gallardo y J. Bergamín. En primer lugar, debe recordarse que el propio nombre de la revista, Hechos e Ideas, coincide con el subtítulo de Leviatán, que Luis Araquistain editaba en Madrid, como instrumento teórico para lograr la radicalización del PSOE; si bien existía en Italia una publicación, dirigida por el historiador L. Dal Pane, que se llamaba Fatti e ldee, tal fórmula no constituia un lugar común entre las publicaciones de izquierda, como por ejemplo lo eran "Claridad", "Combate", "Avance" o "Vanguardia".

La presunción de que existió una apropiación por parte del grupo argentino de algunos elementos de la revista de Araquistain aparece reforzada cuando se recuerdan otras coincidencias: el diseño de tapa, que es absolutamente idéntico; la organización del material, que incluye en muchas ocasiones pequeños subtítulos temáticos sobre un lateral del texto; e inclusive la denominación de algunas secciones fijas. Queremos insistir, en este punto, en que no proponemos la existencia de afinidad ideológica entre ambas publicaciones, ni entre los grupos que apoyaban a Araquistain en el interior del PS español y el radicalismo argentino. Se trata, en cambio, de que estos políticos argentinos se proponen la misma tarea que los españoles se habían planteado, y diseñan una herramienta muy similar, a la que aquellos trataban de organizar.

A los datos que señalamos debe agregarse la reproducción, en Hechoseldeas, del ocasional artículo que Fernando de los Ríos publicara en el número 2 de Leviatán.(50) A su vez, Giustizia e Libertá, el grupo antifascista liberal-socialista, dirigido por Rosselli, Lussu y Salvemini,(51) uno de los primeros en convocar voluntarios cuando estalló la Guerra Civil de España, sostenia una relación bastante estrecha con Hechos e ldeas, tanto a través de la redacción de artículos especiales por parte de Salvemini como mediante la reproducción de notas aparecidas en las publicaciones que GL editaba en París como en algunas clandestinas delinterior; ante el asesinato de los hermanos Roselli por agentes fascistas, la revista rindió su homenaje reiterado al autor de Socialismo liberal. La agrupación italiana se hacia presente a su vez en Leviatán gracias a los artículos y comentarios de libros que publicaba Aurelio Natoli, uno de sus miembros.(52)

A pesar de todas estas circunstancias, cuando la revista argentina escogía los textos a reproducir en el amplio material que Leviatán le brindaba, ejecutaba una operación que hacla evidentes las distancias ideológicas que hemos mencionado: los elegidos son $\mathrm{F}$. de los Ríos o H. Laski, ambos alejados de cualquier intento de "bolchevización". Y, por otra parte, Hechos e ldeas no sólo recogía material de Leviatán: también toma de Cruz y Raya, la revista de Bergamín, el artículo que habia publicado el italiano Luigi Sturzo sobre el totalitarismo.(53) Además, trabajos o discursos de Azaña, Marcelino Domingo, Alvaro de Albornoz, republicanos de izquierda, y del propio Bergamín aparecieron en Hechos e ldeas durante y después de la Guerra Civil, y se saludó, en 1939, la reaparición de Timón, dirigida por Diego Abad de Santillán y Carlos de Baraibar, que luego de su etapa barcelonesa trasladó 
su dirección a Buenos Aires, desplegando una línea fuertemente antiestalinista que coincidía con la de la revista radical.

En realidad, y como hemos anticipado, las zonas de coincidencia más amplias en el pensamiento de estos grupos radicales se daba con el del republicanismo de izquierda. Tanto la confianza en que la "revolución democrática" era todavía posible, comola necesidad de organizar lo que denominaban un "nuevo liberalismo" capaz de extender la democracia a la sociedad, eran compartidas por argentinos y españoles. Del mismo modo, ambos bloques se resistían a pensarse partidos de clase; en el caso argentino, estas concepciones se sesgaban permanentementehacia la fórmula del partido "nacional", mayoritario, interclasista y popular. Esta autoimagen puede vincularse, tanto en españoles como en argentinos, con el afán de saldar la lucha de clases, en favor de los desheredados, apelando ala acción del Estado para favorecer la redistribución de riquezas; en los argentinos, la evaluación de lapolítica rooseveltiana tuvo mucho que ver con la afirmación de estas propuestas, llegando incluso a impactar en sectores socialistas. Esta visión del mundo se manifiesta también en los planteos que la dirección de Hechos e ldeas realiza ante las acciones iniciadas por obreros y campesinos en el período queva del triunfo delFrente Popular al alzamiento militar: "muchos sucesos deplorables se han producido desde la instauración del gobierno republicano de izquierda, pero aquellos deben ser considerados como una consecuencia irremediable de dos años de feroz represión que es lo único que proporcionaron al pueblo de España los gobiernos conservadores". Y, cuando se produzca el levantamiento, la revista argentina se permite señalar que el error de Azaña había sido "no despedazar el latifundio."(54)

Desde la otra orilla, Leviatán también asumía aquellos contactos, aunque sus interlocutores fueran otros. Ya M. Bizcarrondo ha analizado la cuestión del hispanoamericanismo en el pensamiento de Araquistain, y mencionado tanto su intención de dar "proyección latinoamericana" a su revista, como virtudes y defectos del ensayo: presencia de colaboradores hispanoamericanos "mediocres", cierta fragilidad teórica, ausencia de visiones de conjunto, aunque se reconoce elmérito de desplazar hacia la economía las consideraciones culturales clásicas.(55) En nuestro trabajo, a su vez, hemos señalado algunas "pruebas" de que tal preocupación ya existia en Araquistain cuando era director de España, y que ella era compartida por otros individuos.

En el caso de la Argentina, Leviatán establece vínculos con dos revistas: Izquierda y la ya mencionada Claridad. La primera de ella apareció también en 1934, vinculada a los grupos de la izquierda del Partido Socialista argentino; entre quienes conformaban su "comisión de prensa" figuraron Sánchez Viamonte (quien se había contado entre los militantes de la Unión Latinoamericana, de Buenos Aires, en los años veinte), B. Marianetti, B. Fiorini y U. Eyras. Muchos de ellos participaron también en Claridad, que acompañó de cerca, durante cierto tiempo, las posiciones de la izquierda socialista.(56)

En esta oportunidad, las revistas argentinas hacen publicidad de Leviatán y 
reproducen articulos, proclamando la identidad ideológica; la revista de Araquistain, a su vez, publica trabajos de S. Bagú, B. Edelman y R. González Tuñón, miembros de la corriente; recomienda la lectura de ambas revistas y dedica trabajos de los españoles J. Venegas y Carmona Nanclares al problema del socialismo en la Argentina.

Esta izquierda socialista argentina -de manera bastante atinada- insistía en identificar su propio combate en el interior del PS con el que Araquistain desplegaba en España: intentaba la radicalización ideológica de la organización, proponía temas de discusión tales como los métodos para la toma del poder, incluidos los violentos, y criticaba una estrategia estrictamente parlamentarista. Agregaba a estas posiciones, por otra parte, el problema del imperialismo como una cuestión central, tal como hemos indicado y como puede incluso observarse en los artículos que se publican, con firma de los militantes argentinos, en Leviatán.

La tentativa terminó, sin embargo, de modo diverso: la izquierda socialista en la Argentina se dispersó, iniciando en algunos casos una deriva hacia el PC, mientras que otros militantes alentaron la experiencia del Partido Socialista Obrero, que se extinguió con la década; algunos de ellos, en los años cuarenta, brindarán un apoyo claro al peronismo sin abjurar de una perspectiva que pretendian marxista.(57)

III.

En estapanorámica de apoyos, contactos, relaciones, búsquedas de referentes y vecindades en ideas sobre la realidad, se dibujan con fuerza las que sostenían los grupos socialistas y los del democratismo radical españoles y argentinos. Sobre la verificación de su existencia pueden proponerse algunas conclusiones provisorias.

En primer lugar, se destaca la realización de operaciones culturales muy similares, a cargo de intelectuales dedicados a la política: la fundación de editoriales alrededor de publicaciones periódicas; laorganización de circuitos de distribución que a través de la venta en kioscos de colecciones lograban crear, o alcanzar, nuevos grupos de lectores, probablemente "populares"; el objetivo -según parece, apenas alcanzado, tanto en Argentina como en España- de llegar al proletariado, asumiendo una actitud "formativa y aun escolar".(58) Junto a otros procesos, todos los que acabamos de señalar, impulsados por aquellos intelectuales, contribuyeron en la Argentina-en realidad, en Buenos Aires-a la constitución, a lo largo de los años veinte y treinta, de lo que se hallamado "modernidad periférica". Un intento de comparación con la situación española, desplegado desde esta perspectiva, promete resultar particularmente fecundo.

La continuidad y la potencia de la presencia española en el pensamiento político argentino, por otra parte, parece evidente. Es en ese proceso ya más que secular en el que debe instalarse la relación que los argentinos y los españoles vinculados a la tradición radical-democrática y socialista sostuvieron entre sí. Realizar estas afirmaciones no significa apelar a la hipótesis de las "influencias", que la historia 
tradicional de las ideas aplicaba sistemáticamente. Por el contrario, supone plantear que esta relación asumió la forma de un diálogo en el que los americanos sugieren temas y claves de interpretación, al tiempo que, cuando emprenden la tarea de aprehender conceptualmente su realidad, cuentan con diagnósticos, categorías de análisis y propuestas de solución que los españoles habían construido o adaptado de cara a la suya.

El liberalismo democrático español del siglo XIX y sus probables herederos del $X X$, a su vez, consideraron a Hispanoamérica como una entidad existente, como un horizonte posible para la acción política, y no cedieron ni al estado monárquico o dictatorial, ni a la derecha tradicionalista o radical, el patrimonio de la vocación iberoamericana. Esta actitud, y las redes de relaciones que ella habia contribuido a organizar, hallan casi certeza en la base de las políticas que los gobiernos republicanos de izquierda desarrollaron hacia América Latina.(59)

Para la historia de las ideas políticas argentinas, esta confrontación con el universo ideológico español permite insistir en la necesidad de reconsiderar las caracterizaciones atribuidas a ciertos grupos. Los casos de Claridady de Izquierda hacen caer la presunción de que los temas del imperialismo y la nación no figuraban en la agenda de la izquierda argentina en el periodo de entreguerras. Respecto de la Unión Cívica Radical, resulta imposible calificar de "conservadora progresista" a una revista que, como señalamos, critica a Azaña por no haber "despedazado el latifundio", y que cuando comienza la guerra ofrece este diseño de los bandos que se enfrentan:

"Altos jefes militares, borbones, carlistas, grandes terratenientes, formaciones nacionalistas y clericales, todo lo que constituye los vestigios de la edad media, egoísmo exasperado de clase, espiritu de facción, de intolerancia y de violencia, todo lo que se inspira en el fascismo, están aliados en la ofensiva..... contra la República. En nombre de la patria española marchan, con los sicarios de la legión extranjera, contra el pueblo español. Pero el pueblo español tiene conciencia de que está en juego su destino y se ha erguido para detener la marcha con disciplina heroica. Los obreros, los campesinos, los estudiantes y soldados..... forman el ejército de la República..... La lucha popular asume el valor histórico de la epopeya francesa de 1792:.

Desde la lectura del levantamiento como invasión, hasta la referencia al año de Valmy, el complejo de ideas que la revista pone en juego al construir su visión del conflicto la sitúa en una tradición radicalizada y jacobina que compartía con muchos republicanos españoles.

Ya en 1920, el mismo Azaña habia propuesto una interpretación que permite percibir muchas de las ideas que circulaban entre aquellos hombres, revelando con cuanta certeza imaginaban estar librando el mismo combate. En comentario al texto de Manuel Ugarte El porvenir de la América española, donde se reclamaba una vez más la unidad de Hispanoamérica frente al imperialismo, sostenía que "del programa deremedios propuesto..... resultaquelos hispanoamericanos, para no ser devorados 
por los yanquis, necesitan curarse de los mismos defectos y desechar errores muy parecidos a los que, según opinión general, tienen postrada y desvalida a España". Con un tono que anticipa el que utilizaría, años después, en muchas ocasiones, Azaña agrega que se trata de un libro en el que "un espiritu noble concibe una mejor ordenación de las cosas que, luego, implacablemente, no son".(60)

\section{NOTAS}

(1) Ver, por ejemplo, HALPERIN DONGHI, T., "España e Hispanoamérica: miradas a través del Attántico (1825-1975)", en la compilación de trabajos del mismo autor titulada El espejo de la historia. Problemas argentinosy perpectivas latinoamericanas, Sudamericana, Buenos Aires, 1987; y BIAGINI, H. (comp.), Orígenes de la democracia argentina. El trasfondo krausista, Buenos Aires, 1989.

(2) Ver ROMERO. J.L., El desarrollo de las ideas en la sociedad argentina del siglo XX, Solar, Buenos Aires, $1983-1^{2}$ edición mexicana: 1965-, en particular, págs. 87, 92-93, 127 y ss., 134.

(3) Consultar sobre este asunto, PEREZ HERRERO, P.y TABANERA, N. (coords.), España/América Latina: un siglo de politicas culturales, AIETI/Síntesis, Madrid, 1992.

(4) Utilizamos estas denominaciones en el sentido que se le otorga en PRELOT, M., Historia de las ideas politicas, La Ley, Buenos Aires, $1971-1^{2} \mathrm{ed}$. francesa: 1959. Se trata de quienes proponen la necesidad de organizarun "nuevo liberalismo" que se hiciera cargo de la cuestión social; en el período, esta tradición se inclinaba con facilidad a soluciones jacobinas. La extensión de la democracia a la sociedad era otro de sus objetivos proclamados. Ver infra.

(5) Algunos grupos, sin abandonar esa estirpe ideológica, apoyaron incluso al primer peronismo.

(6) Sobre las razones de esta caracterización, y para el tema de la izquierda republicana, ver AVILES FARRE, J., La izquierda burguesa en la II República, Espasa Calpe, Madrid, 1985.

(7) La opinión de Ginzburg puede consultarse en El quesoylos gusanos. El cosmos según un molinero delsiglo XVI, Muchnik, Barcelona, $1981-1^{2} \mathrm{ed}$. italiana: 1976-, en particularpágs. 22 y ss.; yen unfamoso artículo titulado "Señales: raices de un paradigma indiciario", reproducido en Cuadernos de Teoria e Historia la Historiografla, № 14, Biblos, Buenos Aires, 1990.

(8) Puede consultarse, sobre estas cuestiones, la tesis presentada en el Instituto Torcuato Di Tella por CATTANEO, L., La izquierda argentina y América Latina en los años treinta. El caso de "Claridad" Buenos Aires, 1991, págs. 3 y ss. -mimeo-.

(9) Hemos utilizado ya la noción de ideología, objeto de largos debates que no es del caso mencionar aquí. Señalamos que se la utiliza en el sentido de visión del mundo.

(10) Resulta evidente en contra de esta opinión, por ejemplo, que el sistema de ideas de la izquierda argentina sufrí una conmoción profunda alrededor de 1935-1936, cuando el antimperialismo deja de constituir un elemento central en él. Cf., al respecto, CATTANEO, op. cit., passim.

(11) Como ejemplo de estas posiciones puede verse, respecto de la izquierda, WARLEY, J., Vida cultural e intelectuales en la década de 1930, CEAL, Buenos Aires, 1985; págs. 25 y ss. y passim. En cuanto al radicalismo "alvearista" entendido como liberal conservador, o conservador progresista, ver por ejemplo GALLETI, A.., La polltica ylos partidos, FCE, Buenos Aires, 1961, págs. 78-79; HALPERIN DONGHI, T., La democracia de masas, Paidos, Buenos Aires, 1970, pág. 17.

(12) Ver sobre estos temas LOPEZ OCON, L., Biografia de La América. Una crónica hispanoamericana del liberalismo democrático español (1857-1886), CSIC, Madrid, 1987.

(13) Cf. LOPEZ OCON, L., op. cit., págs. 172-173.

(14) Puede consultarse sobre estos temas DELGADO GOMEZ-ESCALONILLA, L. y GONZALEZ CALLEJA, E., "Identidad nacional y proyección transatlántica: América Latina en clave española", año LXXV, fascículo II, separata de Nuova Rivista Storica, 1991.

(15) No desconocemos las discusiones generadas alrededor de la utilización de los términos "Hispanoamérica", "Iberoamérica" y "Latinoamérica". En este trabajo, hemos subordinadola precisión a una cuestión de "estilo", utilizando estos términos como sinónimos que hacen referencia, en todos 
los casos, a la América que fue colonizada por España.

(16) Ver TERAN, O., En busca de la ideología argentina, Catálogos, Buenos Aires, 1986, en particular el articulo titulado "El primer antimperialismo latinoamericano".

(17) Ver NIÑO RODRIGUEZ, "Hipanoamericanismo, regeneración y defensa del prestigio nacional", en PEREZ HERRERO y TABANERA, N. (coords.), op. cit., págs. 19 y ss.

(18) Sobre el impacto del Ariel y la actitud de Leopoldo Alas, ver ABELLAN, J.L., La industria cultural en España, Edicusa, Madrid, 1975, en particularel apartado VII, "Hispanoamérica", cuyo primer articulo se titula "En tomo al Ariel de Rodo". El comentario de Clarin en pág. 334. Respecto a la relación de Altamira con el intelectual uruguayo, y para muchos de los temas que tratamos, consultar NIÑO RODRIGUEZ, A., op.cit., en particular págs. 26 y ss.

(19) Cf. HALPERIN DONGHI, T., “España e Hispanoamérica..., op. cit., págs. 83 a 86.

(20) Cf. el artículo citado de Gómez Escalonilla, págs. 277 y ss.

(21) Consultar, sobre esta cuestión, ROIG, A., Los krausistas argentinos, Cajica, Puebla, 1969, y la citada compilación de Biagini.

(22) Cf., por ejemplo BOTANA, N., El orden conservador. La politica argentina entre 1880 y 1916 , Hyspamérica, Buenos Aires, 1986 -1² edición: 1977-, págs 279 a 283. Sobre la cuestión -más amplia que la que aquí tratamos-de la relación hispanoamericanismo-regeneracionismo, consultar el artículo citado de Niño Rodríguez.

(23) Cf., por ejemplo, los siguientes números de El Socialista, de Madrid: año XXIX, N²1805 03/05/14, pág. 2; y año XXIX, NN21857, 24/06/14, tapa.

(24) Pueden consultarse sobre estas cuestiones SARLO, B., Una modemidad periférica: Buenos Aires 1920 y 1930, Nueva Visión, Buenos Aires, 1988; y ROMERO, L.A., Libros baratos y cultura de los sectores populares. Buenos Aires en la entreguerra, CISEA, Buenos Aires, 1986.

(25) Cf. MAINER, J.C., "Cultura, 1923-1939", en AA.VV., La crisis del estado: Dictadura, República, Guerra (1923-1939), Labor, Barcelona, 1981 [se trata del tomo IX de la Historia de España dirigida por M. Tuñón de Lara], pág. 551. Véase también la "introducción" que E. Montero preparó para la reedición facsimilar de la revista que realiz6 ToposVerlag en 1982. Queremos subrayar, en atención a los planteos que se harán a continuación que el tema hispanoamericanono es el central para España. (26) Cf. entre otros los siguientes números de España:250, 251, 252, 277, 287, 289, 291, 295, 348 y 350 .

(27) Cf. España, año VI, N²94, 27/11/20, pág. 18. Sobre la Reforma Universitaria, véase PORTANTIERO, J.C., Estudiantes y política en América Latina, Siglo XXI, México, 1978; y CIRIA, A. y SANGUINETTI, H., Los reformistas, Ed. J.Alvarez, Buenos Aires, 1968.

(28) Cf., por ejemplo, N² $278,28 / 08 / 20$, pág. 9.

(29) Cf. N²350,30/12/22, pág. 16; y N² 403, 05/01/24, pág. 13.

(30) Cf., sobre Leviatán, BIZCARRONDO, M., Araquistain y la crisis socialista en la II república. Leviatán (1934-1936), Siglo XXI, Madrid, 1975.

(31) Ver en La Pluma, Madrid, № 28, setiembre, 1922, pág. 230, el comentario del libro de Ugarte Mi campaña hispanoamericana. Azaña, por su parte, había elogiado otro trabajo de Ugarte en el $N^{2} 4$, setiembre, 1920, págs. 188-189. Pueden verse también los comentarios bibliográficos de los $\mathrm{N}^{2} 11$ (abril, 1921), 17 (octubre, 1921) y 37 (junio, 1923).

(32) Cf. MAINER, op. cit., pág. 593. A este episodio nos volveremos a referir más adelante.

(33) Sobre Post-Guerra puede consultarse el trabajo de Mainer que hemos citado, en particular págs. 567 y ss.; y CAUDET, F., Las cenizas del Fénix. La cultura española en los años 30, dela Torre, Madrid, 1993, págs. 23-29, 40 y 413-415. De este último libro resultan de particular interés para este punto los capítulos titulados "Vanguardismo, militancia y cultura", "El libro de avanzada en los años 30", y "España: estética de la resistencia". Véase también el libro dememorias que el socialista José Venegas, ya exiliado en Buenos Aires y colaborador de Leviatán, Claridad, Nueva España de Rosario, y de la propia Post-Guerra, publicócon el título Andanzas y recuerdos de España, Montevideo, Feria del Libro, 1943.

(34) Ver CAUDET, op. cit., págs. 122 y ss.

(35) El artículo de Haya apareció en $\mathrm{N}^{2} 5,25 / 10 / 27$, págs. 12-13; en el mismo número, en pág. 3, figura 
la adhesión a la Liga Antimperialista. Los demás datos, respectivamente, en № 8, 29/02/28, pág. 4; y № $6,20 / 12 / 27$, pág. 4.

(36) Cf. Post-Guerra, № 4, 25/09/27, pág. 16.

(37) Sobre Claridad, consultar los siguientes trabajos: MONTALDO, G., "La literatura como pedagogia, el escritor como modelo. Cooperativa Editorial Clanidad: proyecto cultural y empresa comercial", en Cuadernos Hispanoamericanos, julio 1987; de la misma autora "Los pensadores y Claridad. Una propuesta cultural de la izquierda argentina (1922-1942) en América. Cahiers du CRICCAL, París, № 4/5. Ver también el trabajo citado de Cattáneo, y SARLO, B, Una modernidad..., op. cit., en particular págs. 100 y ss., $117,131,144$ y ss.

(38) Lo harán, por ejemplo, Gonzalo de Reparaz en Timón, $2^{2}$ época, Año 1, № 2, Buenos Aires, diciembre, 1939; y Alejandro Casona, en Pensamiento Español, Añoll, Ne XVII, Buenos Aires. PostGuerra realiza sus comentarios en el N² $4,25 / 09 / 27$, en págs. 2, 8 y 9.

(39) Un breve relato del debate puede hallarse en el texto citado de Mainer, pág. 593. Por su parte, CAUDET, F., op. cit., págs. 136-143, enlaza de manera muy sugerente los aspectos económicos y los "ideológicos" involucrados en este debate.

(40) Cf. HALPERIN DONGHI, T., "España e Hispanoamérica.....", op. cit., pág. 79, en referencia a PIKE, F., Hispanismo, 1989-1936....., Notre Dame, 1971, pág. 217.

(41) Ver CAUDET, op. cit., págs. $136-143$.

(42) Cf., La gaceta literaria, N2 50, 15/01/29.

(43) Ct., BARCOS, J.,"La resurrección de España", Prólogo a SORIANO, R, España bajo el sable....., Claridad, Buenos Aires, 1930, pág. VII.

(44) Cf., SORIANO, R., La revolución española: 1931. Ayer y hoy, Ediciones Claridad, Madrid, s/f., pág. 232.

(45) Ver AVILES FARRE, op.cit., pág. 328.

(46) Garcitoral no formó parte del Frente Popular; su evolución ideológica posterior incluý cierta aproximación al catolicismo, y la visión de los Estados Unidos como potencia garante de la democracia. Algunos de los libros que publicó a fines de la década de 1930 y en los años cuarenta (Tercer Frente. Polftica y Espiritu, de 1939; La Tercera República española, de 1941; Interpretación de España, de 1945) llevaban el sello de Claridad. Boffi no sólo presento el trabajo titulado El gran destino. Proceso y misión de los Estados Unidos, Buenos Aires, 1955, sino que publicó un texto laudatorio, llamado A.Garcitoral. His life and work....... New York, 1978.

(47) Cf., la citada Presentación a cargo de Boffi de El gran destino......, citado, págs. 9-10.

(48) Ver los N XIV, junio 1942, y XXI, enero 1943, de Pensamiento Español. Los casos como este abundan; la cuestión de los modos de inserción de los intelectuales exiliados, y de la participación de argentinos en sus emprendimientos, constituye un espacio de investigación que merece un estudio especifico.

(49) Sobre este punto remitimos a PERSELLO,A., "Liberalismoy democracia en el pensamiento radical. Hechos e Ideas 1935-1940", en Anuario, $2^{2}$ época, № 14, Escuela de Historia/Universidad Nacional de Rosario, Rosario, 1989; CATTARUZZA, A., Historia y politica en la década de 1930. Comentarios en torno al caso radical, Biblos, Buenos Aires, 1991; y para un período posterior en la vida de la revista, "Una empresa cultural del primer peronismo: la revista Hechos e Ideas (1947-1955)", en Revista Complutense de Historia de América, Ne 19, Editorial Complutense, Madrid, 1993.

(50) Se trata del artículo titulado "Hacia el estadio corporativo?", que de los Ríos publicó en el № 2 de Leviatán, de junio de 1934. Hechos e Ideas, modificando levemente el título, lo recoge en su $\mathrm{N}^{2} 16$, de octubre de 1936.

(51) La bibliografia referidaal grupoy a su heredero, el Partido de Acción, es muy abundante. Remitimos al volumen colectivo titulado Giustizia e Libertá nella lotta antifascista e nella storia d'ltalia, La Nuova Italia, Firenze, 1978.

(52) Ver, por ejemplo, Leviatán: Ne 2, junio 1934; N² 4, agosto 1934; y Ne 9, enero 1935.

(53) Cf. Cruz y Raya, Madrid, año III, № 28, julio 1935, y Hechos e ldeas, № 16, octubre 1936.

(54) Cf., respectivamente, el № 11/12, de mayo-junio 1936, pág. 23; y el № 14, de agosto de 1936, pág. 8. 
(55) Ver BIZCARRONDO, op. cit., págs. 247,375 y ss.

(56) Véase el trabajo de Cattáneo que citamos con anterioridad.

(57) Así ocurre con J.Coca, M. Unamuno y A. Muzzopapa, que además, mientras apoyanal peronismo, colaboran con una Hechos e ldeas reaparecida que también adhiere al nuevo movimiento.

(58) Ver MAINER, op. cit., pág. 568. Para el caso argentino, consultar los trabajos citados de Sarlo y L.A. Romero.

(59) Ver TABANERA, N., "Institucionalización y fracaso del proyecto republicano", en PEREZ HERRERO,P. Y TABANERA, N, op. cit.

(60) Cf., La Pluma, N², setiembre, 1920, pág. 189. 